\title{
Association of Dark Opening of Stomata with Air Pollution Sensitivity of Irish Potatoes
}

\author{
Atilla B. Goknur ${ }^{1}$ and Theodore W. Tibbitts \\ Department of Horticulture, University of Wisconsin, Madison, WI 53706
}

\begin{abstract}
ADDitional INDEX wORDs. cultivars, Solanum tuberosum, stomatal resistance, stomatal conductance, atmospheric pollutants, fumigations

Abstract. The magnitude of dark opening of stomata on leaves of Irish potato (Solanum tuberosum L.) was studied to determine if this opening was related to the high sensitivity of these plants to air pollutants. Stomatal opening was studied over diurnal periods both in the field and in controlled environments. In both environments, stomatal conductance decreased rapidly at the initiation of dark to $0.1 \mathrm{~cm} \cdot \mathrm{s}^{-1}$ but then increased to $0.2 \mathrm{~cm} \cdot \mathrm{s}^{-1}$ over the dark period. However conductance was always less in the dark than in the light $\left(0.3\right.$ to $\left.0.9 \mathrm{~cm} \cdot \mathrm{s}^{-1}\right)$. During the early part of the dark period, stomatal conductance in controlled environments was not as great as in the field, but conductance was similar in both environments over the latter part of the dark period. Cultivars Norchip and Kennebec had smaller conductances during the first hours of the dark than Haig or Katahdin, and all cultivars increased in conductance over the dark period. 'Haig' showed slightly higher conductance than the other three during the last 4 hours of the dark period. Injury to 'Haig' from 3-hour fumigations with sulfur dioxide $\left.\mathrm{SO}_{2}\right)$ or ozone $\left(\mathrm{O}_{3}\right)$ demonstrated that exposures during the day generally produced more injury than during the night, although exposures with $\mathrm{SO}_{2}$ during the last 3 hours of the light period produced similar injury to exposures at the end of the dark period. Thus, although partial opening during the dark may be permitting some pollution injury, it is concluded that previous published reports of similar opening of stomata on Irish potatoes during the light and dark periods, and equal or greater pollution injury during the dark compared with the light period, were not substantiated and apparently resulted from procedural artifacts.
\end{abstract}

Irish potatoes (Solanum tuberosum) have been reported to exhibit significant dark opening of stomata (Loftfield, 1921; Nielson, 1938) and have also been shown to be one of the most sensitive herbaceous plants to ozone $\left(\mathrm{O}_{3}\right)$ pollution (Foster et al., 1983; Heggested, 1973, Hooker et al., 1973; Mosley et al., 1978). Thus, stomatal opening during the dark may be contributing to the sensitivity of Irish potatoes to air pollutants. This response of potatoes is in contrast to most other herbaceous plants, which close stomata tightly during dark periods and are relatively insensitive to air pollutants during the dark period. The two studies of pollution sensitivity of Irish potatoes during the dark have led to conflicting conclusions. Heggested (1973) found greatly reduced injury when exposing them to $\mathrm{O}_{3}$ in a dark enclosure. However Nielson (1938) reported as much injury in the dark as in the light.

The objective of this study was to establish if Irish potatoes have wide-open stomata during dark periods and if this predisposes them to a high degree of pollution injury. Stomatal opening of in situ plants through $24 \mathrm{~h}$ periods in both field and controlled environments was determined and this was followed by studies to determine the impact of sulfur dioxide $\left(\mathrm{SO}_{2}\right)$ and $\mathrm{O}_{3}$ exposures at different times during dark and light periods.

\section{Materials and Methods}

\section{Cultural practices}

FIELD. 'Norchip' and 'Kennebec' Irish potatoes were grown in irrigated Plainfield sand at the Hancock Experimental Station, $43^{\circ}$ north latitude, near Hancock, Wis. Seed pieces were planted

Received for publication 25 Oct. 1999. Accepted for publication 12 Sept. 2000 Research supported by the College of Agricultural and Life Sciences, Univ. of Wisconsin, Madison, and the Wisconsin Power and Light Company. The cost of publishing this paper was defrayed in part by the payment of page charges. Under postal regulations, this paper therefore must be hereby marked advertisement solely to indicate this fact.

${ }^{1}$ Current address: 25 Jacobs Court, Madison, WI 53711. on 15 April 1984, at $30 \mathrm{~cm}$ in-row spacing and $90 \mathrm{~cm}$ betweenrow spacing. The field was fertilized with $\mathrm{N}, \mathrm{P}$, and $\mathrm{K}$ at planting and additional nitrogen at emergence and hilling. Herbicides were used at planting, fungicides were used weekly for blight, and insecticides applied as needed. Overhead irrigation was used. Stomatal data were collected from 11 to 20 June, when plants had four to five branching stems and 9 to 12 leaves over $5 \mathrm{~cm}$ in length on each stem. Temperature, irradiance, and humidity were recorded manually at about $2 \mathrm{~h}$ intervals at the field site. During the period of sampling reported in this paper (11 to 12 and 19 to 20 June), air temperatures ranged from 18 to $29^{\circ} \mathrm{C}$ during the day and 15 to $20{ }^{\circ} \mathrm{C}$ during the night (Fig. 1A). Relative humidity $(\mathrm{RH})$ ranged between $46 \%$ to $67 \%$ during the day and $68 \%$ to $84 \%$ during the night (Fig. 1B). Vapor pressure deficits ranged from 0.5 to $2.8 \mathrm{kPa}$ during the day and 0.2 to $0.5 \mathrm{kPa}$ during the night (Fig. 1C). Irradiance was measured with a LI-185 quantum sensor (LI-COR, Lincoln, Nebr.), except during moonlight and early dawn when a spectroradiometer (EG\&G; Gaithersburg, Md.) with sensitivity below $0.1 \mu \mathrm{mol} \cdot \mathrm{m}^{-2} \cdot \mathrm{s}^{-1}$ was used. The days were partly cloudy with maximum photosynthetic photon flux $(P P F)$ exceeding $2000 \mu \mathrm{mol} \cdot \mathrm{m}^{-2} \cdot \mathrm{s}^{-1}$ when the sun was bright and below $1000 \mu \mathrm{mol} \cdot \mathrm{m}^{-2} \cdot \mathrm{s}^{-1}$ when clouds obscured the sun. The sun was generally obscured by clouds during dawn and dusk. The PPF levels during dawn and dusk periods are provided in Table 1.

ConTrolled ENVIronment. Plants were propagated by meristem culture. 'Haig', 'Norchip', 'Katahdin', and 'Kennebec' Irish potatoes were used for the stomatal studies whereas only 'Haig' was grown for the pollutant exposure studies. After $15 \mathrm{~d}$ in culture, uniform plantlets were planted into 1.5 -L containers filled with a medium of 1 peat : 1 vermiculite (v:v). All pots were watered to excess with nutrient solution (Hammer et al., 1978) four times daily. Plants were grown in a controlled environment room in the University of Wisconsin Biotron, Madison, for 21 to $28 \mathrm{~d}$. Stomatal data and pollution exposures were undertaken when the main stem of the plants had 11 to 13 leaves over $5 \mathrm{~cm}$ in length. Light was provided by cool-white fluorescent lamps for $12 \mathrm{~h} \cdot \mathrm{d}^{-1}$ with all lamps turned on and off at the same time. The 

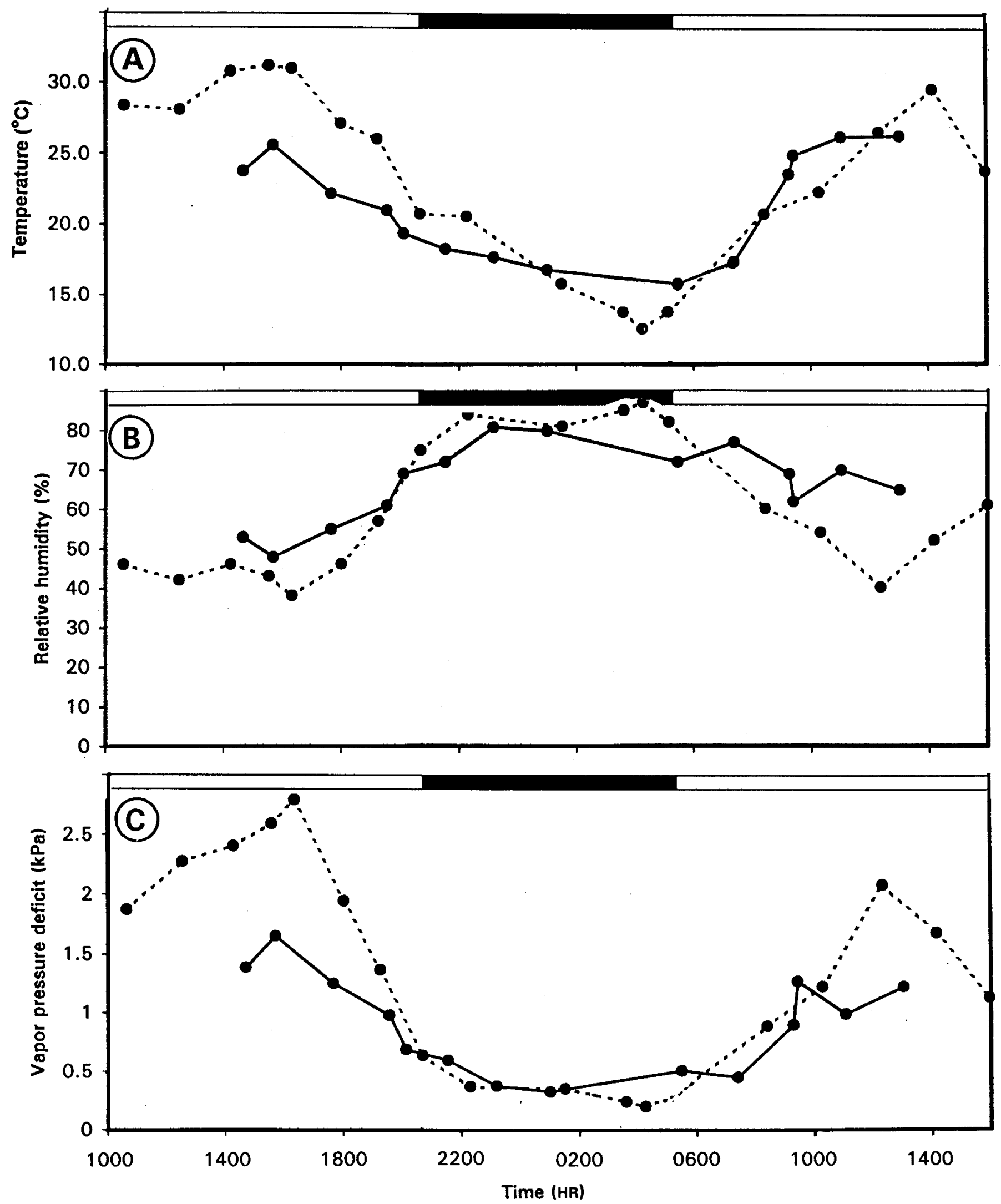

Fig. 1. (A) Temperature, (B) relative humidity, and (C) vapor pressure deficit of the air in the field on 11 to 12 June (solid lines) and 19 to 20 June (dashed lines). The solid bar at the top of the figure encompasses the period of 'darkness' between sunset and sunrise. Sunset and sunrise, were at 2043 and 0514 $\mathrm{HR} \pm 2 \mathrm{~min}$, respectively, on these sampling dates. 
Table 1. Recorded evening and morning ${ }^{\mathrm{z}}$ levels of photosynthetic photon flux $(P P F)$.

\begin{tabular}{|c|c|c|c|}
\hline $\begin{array}{l}\text { Time } \\
\text { (HR) }\end{array}$ & $\begin{array}{c}P P F \\
\left(\mathrm{mmol} \cdot \mathrm{m}^{-2} \mathrm{~s}^{-1}\right)\end{array}$ & $\begin{array}{l}\text { Time } \\
(\mathrm{HR})\end{array}$ & $\begin{array}{c}P P F \\
\left(\mathrm{mmol} \cdot \mathrm{m}^{-2} \mathrm{~s}^{-1}\right)\end{array}$ \\
\hline \multicolumn{2}{|c|}{ Evening 11 June } & \multicolumn{2}{|c|}{ Evening 19 June } \\
\hline 1834 & 400 & 1820 & 535 \\
\hline 1930 & 160 & 1915 & 245 \\
\hline 2007 & 45 & 2041 & 10.5 \\
\hline 2022 & 26 & 2108 & 0.4 \\
\hline 2035 & 12 & 2217 & dark \\
\hline 2132 & dark & & \\
\hline \multicolumn{2}{|c|}{ Morning 12 June } & \multicolumn{2}{|c|}{ Morning 20 June } \\
\hline 0528 & 14 & 0416 & Dark \\
\hline 0548 & 38 & 0508 & 1.7 \\
\hline 0722 & 100 & 0535 & 17 \\
\hline 0740 & 195 & 0542 & 24 \\
\hline 0915 & $>1000$ & 0824 & $>1000$ \\
\hline
\end{tabular}

${ }^{\mathrm{z}}$ Sunrise and sunset were at 0514 and $2043 \mathrm{HR} \pm 2 \mathrm{~min}$, respectively, on these sampling dates.

$12 \mathrm{~h}$ dark cycle was scheduled from 0900 to $2100 \mathrm{HR}$ to minimize power usage during critical afternoon hours. $P P F$ levels were maintained at plant height as measured with a LI-185 quantum meter(LI-COR). Temperature was measured with thermocouples at canopy height in the center of the room. RH was measured with an aspirated thermocouple psychrometer. Air velocity was monitored with a hot-wire anemometer (Anemotherm model 60; Halton Co., Scottsville, Ky.). The carbon dioxide concentration was measured at the top of the plant canopy with an infrared carbon dioxide analyzer. For the studies of stomatal opening, $P P F$ was $410 \pm 25 \mu \mathrm{mol} \cdot \mathrm{m}^{-2} \cdot \mathrm{s}^{-1}$, temperature was $23 \pm 0.7^{\circ} \mathrm{C}, \mathrm{RH}$ was $73 \pm 5 \%$, and carbon dioxide concentration was $330 \pm 10$ $\mu \mathrm{L} \cdot \mathrm{L}^{-1}$. For studies with pollution exposures, $P P F$ was $350 \pm 20$ $\mathrm{mmol} \cdot \mathrm{m}^{-2} \cdot \mathrm{s}^{-1}$, temperature was $23 \pm 2{ }^{\circ} \mathrm{C}$, relative humidity was $68 \pm 10 \%$, and carbon dioxide concentrations were maintained at $\approx 330 \mu \mathrm{L} \cdot \mathrm{L}^{-1}$ with a large supply of outside air. Constant diurnal temperatures were used in the controlled environment studies to avoid diurnal fluctuations in vapor pressure deficits and thus in moisture stress on the plants. This contrasted with the light and dark period fluctuations in vapor pressure deficits and in moisture stress in the field. Irish potatoes are known to develop normally at constant temperatures, however, growth may be slower than with alternating temperatures for some cultivars (Bennett et al., 1991).

\section{Stomatal resistance measurements}

Stomatal conductance was measured both in the controlled environment and in the field with an L1-700 automatic diffusive resistance porometer equipped with a horizontal sensor (LICOR). The meter and sensor were calibrated at the prevailing temperature just before and after measurement with a pore plate of known resistance. In the field, adjustments for temperature and humidity changes were made by constructing new calibration curves for each increment of $5^{\circ} \mathrm{C}$ change.

Measurements were taken from the second most distal leaflets of the $2 \mathrm{nd}, 3 \mathrm{rd}$, 4th, and 5th fully expanded leaves numbered consecutively from the base of a stem. These distal leaflets were not shaded by other leaflets. Measurements were taken every $2 \mathrm{~h}$ during a $24 \mathrm{~h}$ cycle on four plants at each measurement time in controlled environments and on six plants in the field. Since initial experiments indicated that leaf sampling at least $2 \mathrm{~h}$ or more apart did not have any effect on stomatal conductance of leaves, the same leaves were sampled no more frequently than every $2 \mathrm{~h}$ and typically only every $4 \mathrm{~h}$ (Goknur, 1987). The abaxial and adaxial stomata responded similarly over the light and dark periods with much greater conductance on the abaxial than adaxial surface (Goknur, 1987). Thus, abaxial measurements were used because of the larger number of stomata and thus less variability between successive readings. Measurements of stomatal response in the field were not reported for other diurnal periods between 12 and 19 June, because condensation formed on the leaves late in the night of these dates and caused erroneously high conductance readings.

\section{Pollutant exposures}

Plants were exposed to pollutants in $75 \times 75 \times 100 \mathrm{~cm}$ Plexiglas chambers, positioned in larger chambers in a room of the University of Wisconsin Biotron. Three of these chamber units were used for the pollutant exposures. A single pass exposure system was used with pollutant added to the incoming air to maintain the desired concentrations as monitored at plant height at the center of the chamber. Fans were positioned within each exposure chamber to circulate air. The exposure chambers were maintained at the same temperature and $\mathrm{RH}$ as provided in the chambers used for the growth of plants. Irradiance was provided by four 50-W incandescent bulbs and two 400-W high-pressure sodium lamps (Lumalux, Sylvania Inc., Danvers, Mass.) instead of cool-white fluorescent lamps used in the growing chambers.

Plants were exposed to the pollutants when they had developed 8 to 10 fully extended leaves (14 to 15 leaves per plant) between 20 and $24 \mathrm{~d}$ after transferring the micropropagated stem cuttings to growing medium. Plants were taken from the growth chambers and placed in the exposure chambers for $3 \mathrm{~d}$ before pollutant exposures to acclimate to the exposure chambers. For all exposures, 12 plants were placed in an exposure chamber and fumigated for $3 \mathrm{~h}$. Each exposure was replicated on separate groups of 12 plants.

Exposures at different periods over the dark/light cycle were scheduled with $\mathrm{SO}_{2}$ at a concentration of $1.75 \mathrm{~mL} \cdot \mathrm{L}^{-1}$, a concentration found in preliminary studies to cause some injury at all exposure times. These exposures were undertaken at the beginning, middle, and end of both the dark and light periods at 0.5 to $3.5 \mathrm{~h}, 4.5$ to $7.5 \mathrm{~h}$, and 8.5 to $11.5 \mathrm{~h}$. The exposure at 8.5 to $11.5 \mathrm{~h}$ after the start of the dark period was repeated in each set of three fumigations to compare reproducibility of the repeated fumigations.

Dose response curves for $\mathrm{SO}_{2}\left(0.75\right.$ to $\left.2.75 \mathrm{~mL} \cdot \mathrm{L}^{-1}\right)$ and $\mathrm{O}_{3}$ ( 0.05 to $\left.0.45 \mathrm{~mL} \cdot \mathrm{L}^{-1}\right)$ were made with exposures at 4.5 to $7.5 \mathrm{~h}$ after the start of the light and 8.5 to $11.5 \mathrm{~h}$ after the start of the dark periods. These particular periods were used because they gave the greatest injury from $\mathrm{SO}_{2}$ during the light and dark periods, respectively. These concentrations ranges were expected, on the basis of preliminary studies, to produce from slight to severe injury to the plants.

Sulfur dioxide was obtained from a gas cylinder containing $0.1 \% \mathrm{SO}_{2}$ in nitrogen with flow to the mixing plenum regulated by a needle valve. The $\mathrm{SO}_{2}$ concentrations were monitored continuously with a pulsed fluorescent analyzer (model 43; ThermoElectron, Waltham, Mass.). Ozone was generated with ultraviolet lamps and monitored with a chemiluminescent ozone analyzer (model 8410; Monitor Labs, San Diego, Calif.). Both analyzers were calibrated with a gas phase titration calibrator (model 8861DA; Bendix, Baltimore, Md.). 


\section{Leaf injury measurements}

Each leaf over $5 \mathrm{~cm}$ in length on the plants was examined for chlorotic and necrotic injury when maximum injury had resulted, 5 to $6 \mathrm{~d}$ after exposure to pollutants. Injury from $\mathrm{SO}_{2}$ occurred as 0.2 to $0.5 \mathrm{~cm}$ necrotic or chlorotic areas scattered across the leaf. Injury from $\mathrm{O}_{3}$ was seen as necrotic blackish flecks appearing primarily only on the lower surface of the leaves. Injury was recorded as percentage of the leaves on each plant that exhibited necrotic or chlorotic injured areas.

\section{Data analysis}

Data are reported as mean $\pm \mathrm{SE}$. Where appropriate, treatment means were subjected to analysis of variance procedures and means separated by Duncan's multiple range test. Linear and power regression equations were provided for injury from pollution exposures.

\section{Results}

\section{Stomatal opening}

FIELD. The dark response of stomata of Irish potatoes in the field was similar to that on plants grown in controlled environments. Stomatal conductances of field-grown 'Kennebec' and 'Norchip', were $0.1 \mathrm{~cm} \cdot \mathrm{s}^{-1}$ about $2 \mathrm{~h}$ after complete darkness (Fig. 2). Stomatal conductances started to increase gradually in both cultivars after $2 \mathrm{~h}$ of darkness and this increase in conductance continued throughout the dark period, indicating a progressive opening of stomata during the dark. As dawn broke, there was an additional increase in conductance that reached a maximum $\left(0.9 \mathrm{~cm} \cdot \mathrm{s}^{-1}\right) 4$ to $5 \mathrm{~h}$ after the time of sunrise. Over the day, the stomata had a gradual small closure and during the last 3 to $4 \mathrm{~h}$ the conductance had decreased to $0.3 \mathrm{~cm} \cdot \mathrm{s}^{-1}$.

Controlled ENVIRonMenTs. Stomata of all cultivars grown in controlled environments were closed most tightly (i.e., conductances were least) at the beginning of the dark period, with a minimum stomatal conductance of 0.04 to $0.06 \mathrm{~cm} \cdot \mathrm{s}^{-1}$ for 'Kennebec' and 'Norchip' and 0.09 to $0.10 \mathrm{~cm} \cdot \mathrm{s}^{-1}$ for 'Katahdin' and 'Haig' (Fig. 3). 'Kennebec' and 'Norchip' showed greater stomatal closure at the beginning of the dark period, but they exhibited a large increase in stomatal conductance over the dark period. During the last hours of the dark period their conductance was similar to that of 'Katahdin' and 'Haig'. All cultivars reached maximum dark opening about $1 \mathrm{hr}$ before the light period began, with a stomatal conductance of 0.17 to $0.24 \mathrm{~cm} \cdot \mathrm{s}^{-1}$ for the four cultivars. Within $2 \mathrm{~h}$ after the lights were turned on, stomata of all cultivars reached maximum opening ( 0.75 to $0.90 \mathrm{~cm} \mathrm{~s}^{-1}$ conductance) and remained at a similar conductance level for the next $6 \mathrm{~h}$. During the last $6 \mathrm{~h}$, conductances decreased to 0.25 to $0.30 \mathrm{~cm} \cdot \mathrm{s}^{-1}$ before the lights were turned off.

\section{Pollutant fumigations}

Injury to Irish potato plants exposed for $3 \mathrm{~h}$ at the different times during the light and dark period with the same concentration of $\mathrm{SO}_{2}$ $\left(1.75 \mathrm{~mL} \cdot \mathrm{L}^{-1}\right)$ is illustrated in Fig. 4. During the light, plants exhibited the greatest injury when exposed during the middle of the period and the least injury at the end of the period. During the dark, plants had some injury for each exposure time, but injury was greater at the end than at the beginning or middle of the dark period. The amount of injury with exposures at the end of the dark period was similar to the injury from exposures at the end of the light period.

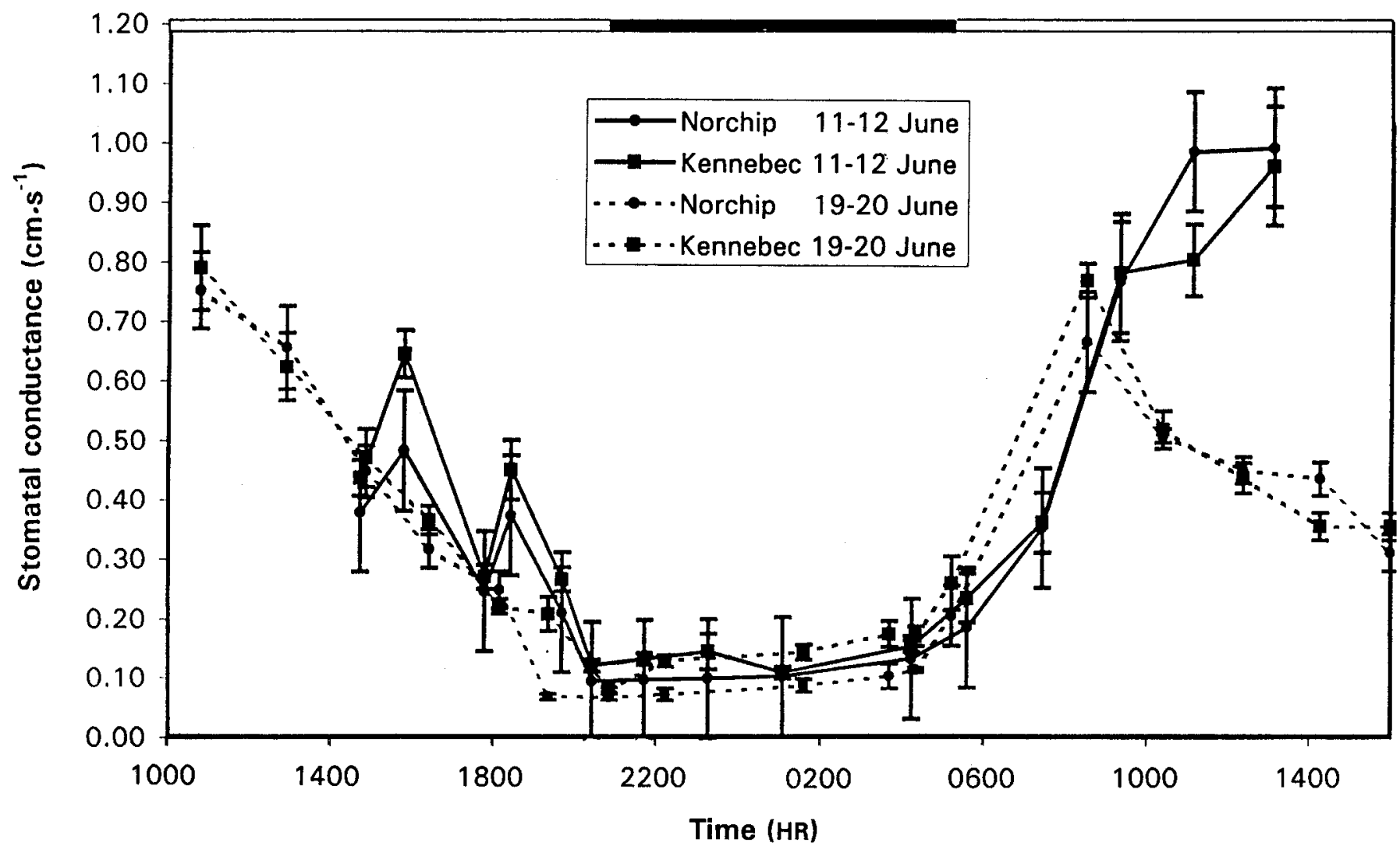

Fig. 2. Stomatal resistance of 'Norchip' and 'Kennebec' Irish potatoes grown under field conditions. Values are the means \pm SE of one measurement on each of six plants. The solid bar at the top of the figure encompasses the period of 'darkness' between sunset and sunrise. Sunset and sunrise, were at 2043 and $0514 \mathrm{HR} \pm 2$ min, respectively, on these sampling dates. 


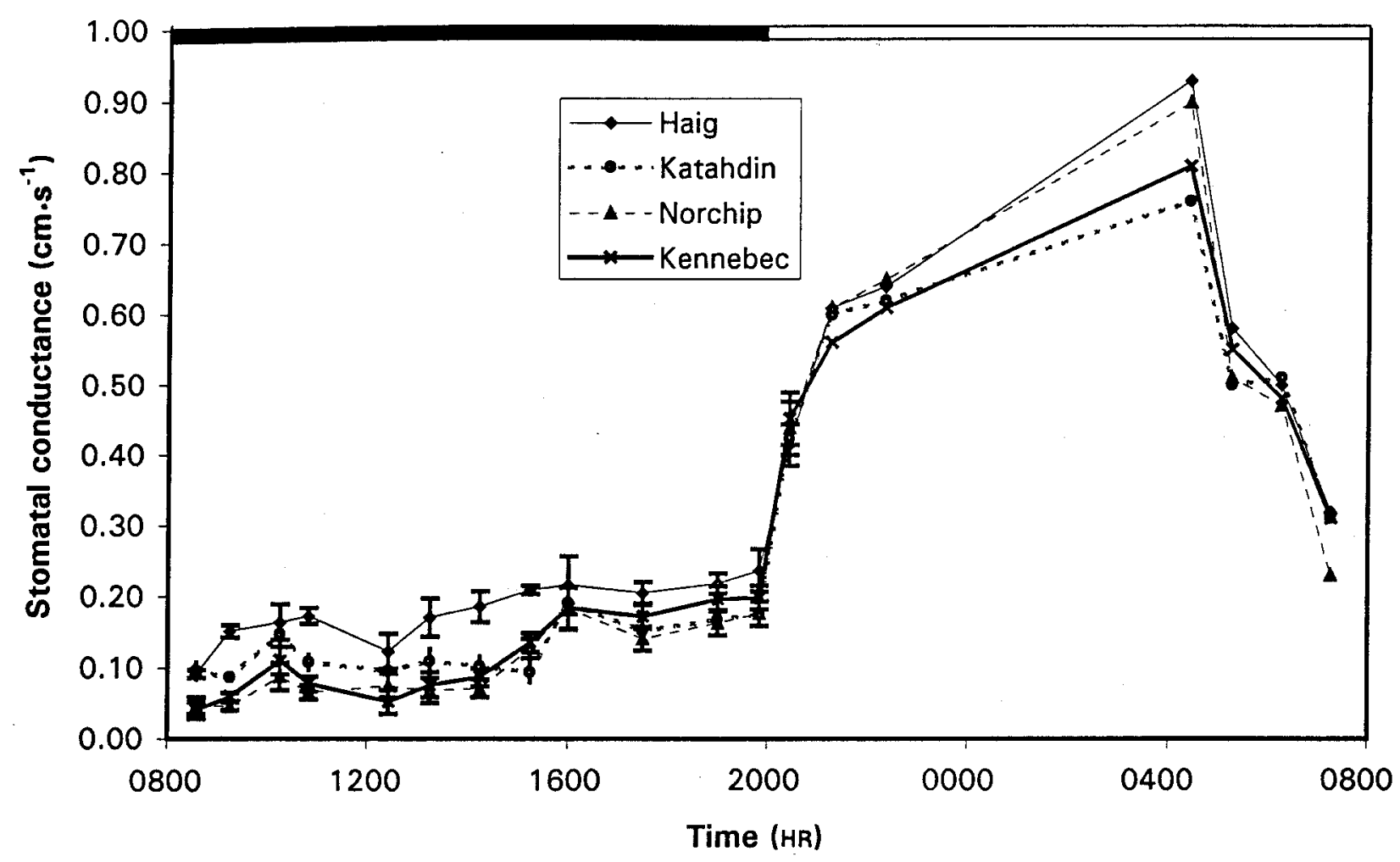

Fig. 3. Stomatal resistance of 'Norchip', 'Kennebec', 'Haig', and 'Katahdin' Irish potatoes grown in controlled environments. Values are means \pm SE of one measurement on each of four plants. Solid bar at the top of the figure indicates the dark period.

Dark period exposures with $\mathrm{SO}_{2}$ showed a peculiar symptom of injury that was not present with light period exposures. Injury on older leaves consisted of brownish-black necrotic areas near the midvein that were restricted to the upper surfaces of leaves. These necrotic spots, 2 to $4 \mathrm{~mm}^{2}$ in diameter, covered about $5 \%$ of the total leaf area in the most severe cases.

Injury to Irish potatoes with different concentrations of $\mathrm{SO}_{2}$ demonstrated that exposures to $1.75 \mathrm{~mL} \cdot \mathrm{L}^{-1} \mathrm{SO}_{2}$ for $3 \mathrm{~h}$ at the time of maximum sensitivity in the dark period produced a level of injury similar to that produced by $1.25 \mathrm{~mL} \cdot \mathrm{L}^{-1} \mathrm{SO}_{2}$ at the time of maximum sensitivity in the light period (Fig. $5 \mathrm{~A})$. Thus, $\approx 1.5$ times more $\mathrm{SO}_{2}$ was required in the dark than in the light to produce similar amounts of injury in the two time periods. This correlation was consistent for all $\mathrm{SO}_{2}$ concentrations studied.

The injury to Irish potatoes with different concentrations of ozone demonstrated that exposures to $0.45 \mathrm{~mL} \cdot \mathrm{L}^{-1} \mathrm{O}_{3}$ for 3 $\mathrm{h}$ at the end of the dark period produced a level of injury similar to that produced by 0.10 $\mathrm{mL} \cdot \mathrm{L}^{-1}$ during the middle of the light period (Fig. 5B). Thus, there was a greater difference with $\mathrm{O}_{3}$ than with $\mathrm{SO}_{2}$ in the amount of pollutant required to produce similar levels of injury during periods of maximum sensitivity in the dark and light.

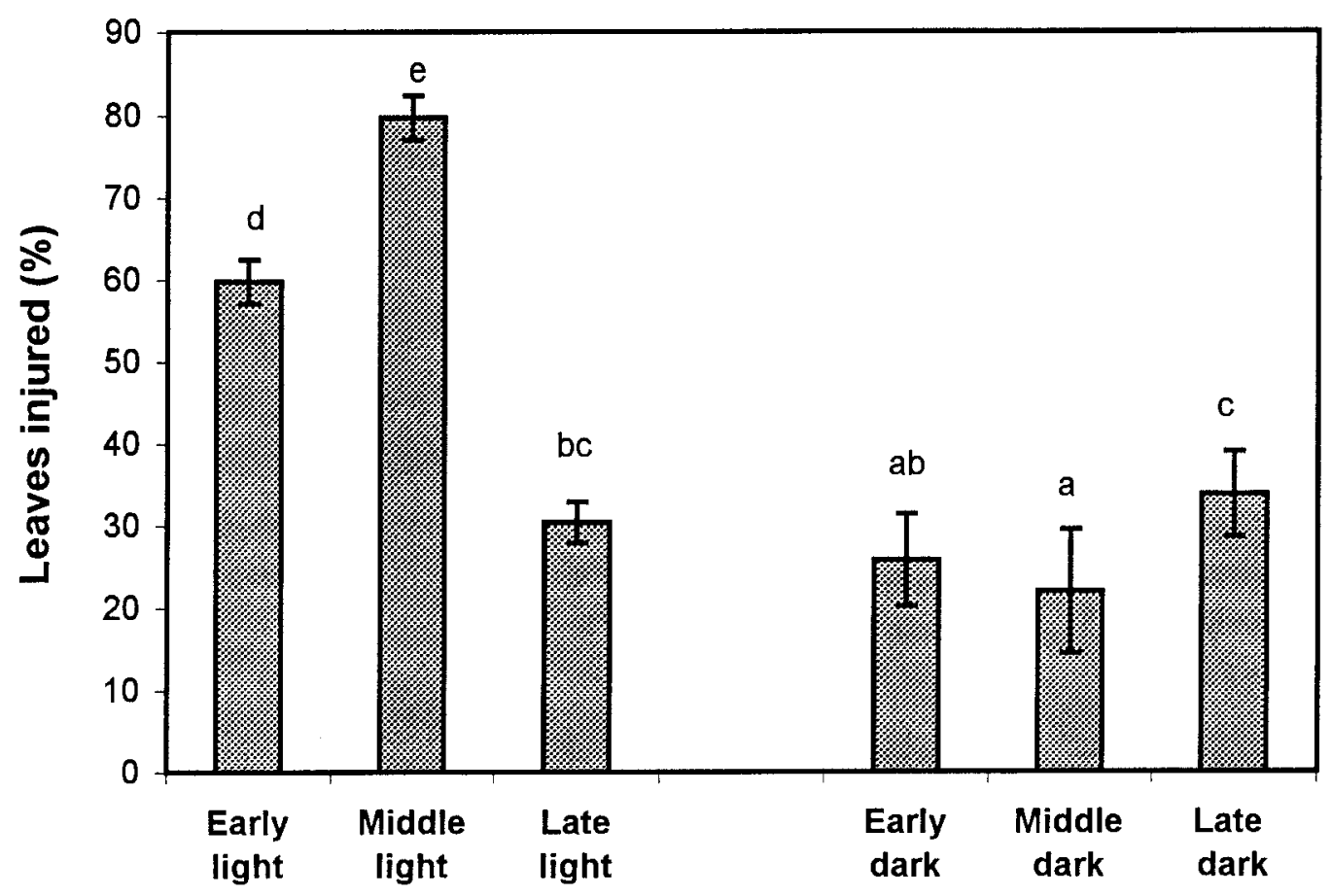

Fig. 4. Leaf injury to Irish potato plants exposed to $1.75 \mathrm{~mL} \cdot \mathrm{L}^{-1} \mathrm{SO}_{2}$ for $3-\mathrm{h}$ intervals at three successive times during both the light and dark periods. Values are means \pm SE of 12 different plants. Mean separation by Duncan's multiple range test at $P \leq 0.05$. 


\section{Discussion}

Stomatal conductance measurements, obtained from plants grown both in controlled and field environments, demonstrated that stomata of Irish potatoes closed significantly at the onset of dark. This was followed by a slow opening throughout the dark period, that resulted in at least a 50\% increase in stomatal conductance from early to late in the dark period. However, the maximal stomatal opening in the dark was always less than the opening recorded in the light. These results are in contrast with earlier reports that Irish potato stomata open as widely at night as in daytime (Loftfield, 1921; Nielson, 1938). Two possible explanations for this are, the alcohol-fixation technique used in these earlier studies to measure stomatal opening has been shown to give erroneous opening values
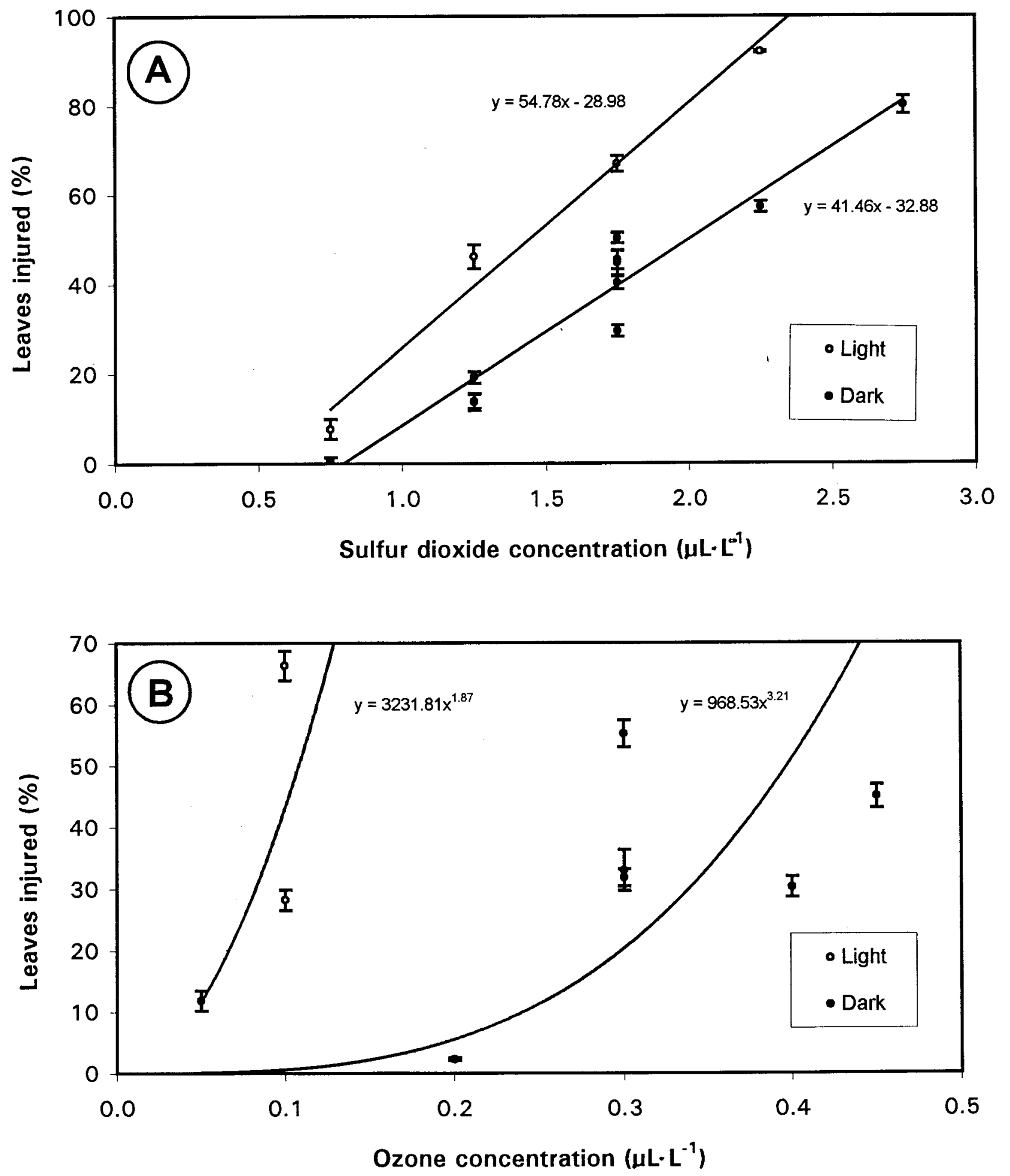

Fig. 5. Leaf injury to 'Haig' Irish potato plants exposed to (A) $\mathrm{SO}_{2}$ or $(\mathbf{B}) \mathrm{O}_{3}$ during the light and dark. The dark exposures were made during the last $3 \mathrm{~h}$ of the $12 \mathrm{~h}$ of dark and the light exposures at the middle of the $12 \mathrm{~h}$ of light. Values are the means \pm SE of 12 different plants. 
since it tends to cause opening of stomata when stomata are mostly closed and closure when stomata are wide open (Hsiao and Fischer, 1975). Second, differences in environmental conditions could have an important role in differences observed between studies. Irradiances in the controlled environment studies of Nielson (1938) were only about one-fourth the level in these present studies. A low light level would tend to produce less opening of stomata during the light period and decrease the difference in opening between dark and light (Turner, 1991). Also, differences in water stress on plants in the different studies may have influenced night opening as reported by Loftfield (1921). However moisture is of questionable significance for extensive studies of soil moisture stress and atmospheric stress on Irish potatoes over the growth period was not found to induce greater opening during the dark than in the light by Goknur (1987). He found that soil moisture stress reduced opening during both the light and the dark periods but potatoes still had a greater amount of opening in the light than in the dark. He also observed that atmospheric moisture stress had little impact upon the opening response at any time.

Stomatal opening toward the end of the dark period has been reported by several investigators (Meidner and Mansfield, 1968, Ziegler et al., 1981). The dark opening reported for most plant species has been relatively small and usually starts only 1 to $2 \mathrm{~h}$ before the time of irradiation. However for Irish potatoes, the dark opening movement began a few hours after initial closure and continued steadily throughout the dark period.

In the study reported herein, there were differences between cultivars in the dark response of stomata. The cultivars in controlled environments with lowest stomatal conductances at the start of the dark period, 'Norchip' and 'Kennebec', showed a faster dark opening response but were similar to the other cultivars by the end of the dark period. The cultivars grown in field conditions, 'Norchip and Kennebec', exhibited an opening at the end of the dark period similar to the controlled environment plants, even though they showed higher stomatal conductances at the start of the dark period. Differences and similarities observed between cultivars may be due to the particular cultivar-environment interactions that plants were subjected to in the field and controlled environments of this study.

The pollution exposures reported in this present study indicate that Irish potato plants are less sensitive to pollutants in the dark period than in the light period. This reduced sensitivity of potatoes during the dark period is in contrast to a previous report that potatoes are more or equally sensitive to $\mathrm{SO}_{2}$ during the dark than in the light (Nielson, 1938). Difference between results of Nielson (1938) and results of our study likely arose from the level of lighting and from the protocol for the dark exposures. In Nielson's 1938 study, irradiances were about one-fourth of the irradiances of the present studies. The lower light in his study would tend to produce a smaller degree of stomatal opening and thus reduce the amount of pollutant entering the leaf tissue in a given period of time (Katzand Ledingham, 1939; Mansfield, 1973; Olszyk and Tibbitts, 1981) and decrease the amount of injury during the light period. Also for the dark pollutant exposures, the plants of Nielson were maintained in the dark for $24 \mathrm{~h}$ before the exposures. This extended dark period would have encouraged a maximum amount of dark opening and have increased the sensitivity of the leaves to injury.

Our results with $\mathrm{O}_{3}$ are in agreement with a previous study by Heggested(1973), who found that $\mathrm{O}_{3}$ was much less injurious during the dark than during the light period. Nonetheless, the partial opening of stomata in the dark may contribute to the relatively high sensitivity of potatoes to ozone pollution in field environments (Foster et al., 1983; Heggested, 1973; Mosley et al., 1978).
Comparing between $\mathrm{SO}_{2}$ and $\mathrm{O}_{3}$ for the concentration of pollutant necessary to produce similar injury during the light and dark, it is evident that $\mathrm{O}_{3}$ is of less relative concern during the dark period than $\mathrm{SO}_{2}$. A four times greater $\mathrm{O}_{3}$ concentration was required in the dark to cause injury levels similar to those produced with fumigations in the light, whereas only about one and one-half times greater $\mathrm{SO}_{2}$ concentration was required in the dark. This difference likely resulted from the fact that in the light, $\mathrm{SO}_{2}$ is rapidly detoxified within the leaves to sulfite and sulfate, thus reducing its injurious effects (Olszyk and Tingey, 1984). No particular light-induced detoxification has been reported for $\mathrm{O}_{3}$. However, also during exposures, $\mathrm{SO}_{2}$ and $\mathrm{O}_{3}$ have been shown to have direct effects on stomatal opening. Sulfur dioxide caused the stomata of plants to open in the dark whereas $\mathrm{O}_{3}$ caused the stomata to close more tightly (Elkiey and Ormrod, 1979; Olszykand Tibbitts, 1981; Tibbitts and Kobriger, 1983).

It would have been desirable to track stomatal activity during pollutant exposures, however, these data could not be obtained with our exposure apparatus. Investigations of gas exchange using closed chambers would allow documentation of the effects of $\mathrm{SO}_{2}$ and $\mathrm{O}_{3}$ exposures on stomatal response of potatoes in darkness.

In conclusion, we demonstrated that stomata on Irish potatoes close significantly at the onset of a dark period and then exhibit a gradual opening throughout the dark period. Thus Irish potato plants were less sensitive to $\mathrm{SO}_{2}$ and $\mathrm{O}_{3}$ during the dark period than during the light period, but sensitivity increased toward the end of the dark period as stomatal conductance increased.

\section{Literature Cited}

Bennett, S.M., T.W. Tibbitts, and W. Cao. 1991. Diurnal temperature fluctuation effects on potatoes grown with $12 \mathrm{hr}$ photoperiods. Amer. Potato J. 68: 81-86.

Elkiey, T. and D.P Ormrod. 1979. Leaf diffusion resistance responses of three petunia cultivars to ozone and/or sulfur dioxide. J. Air Pollut. Control Assn. 6:622-625.

Foster, K.W., J.P. Guerand, R.J. Oshima, J.C. Bishop, and H. Timm. 1983. Differential ozone susceptibility of 'Centennial Russet' and 'White Rose' potato as demonstrated by fumigation and antioxidant treatments. Amer. Potato J. 60:127-139.

Goknur, A.B. 1987. Dark opening of potato stomata and its relation to pollutant sensitivity. PhD diss. Univ. Wis., Madison.

Hammer, P.A., T.W. Tibbitts, R.W. Langhans, and J.C. McFarlane. 1978. Base-line growth studies of 'Grand Rapids' lettuce in controlled environments. J. Amer. Soc. Hort. 103:649_ 655 .

Heggested, H.E. 1973. Photochemical air pollution injury to potatoes in the Atlantic coastal states. Amer. Potato J. 50:315-328.

Hooker, W.J., T.C. Yang, and H.S. Potter. 1973. Air pollution injury of potato in Michigan. Amer. Potato J. 50:151-161.

Hsiao, T.C. and R.A. Fischer. 1975. Microscopic measurements of stomatal aperture and diffusive resistance, p. 2-5. In: E.T. Kanemasu (ed.). Measurement of stomatal aperture and diffusive resistance. Washington State Univ. College Agr. Res. Sta. Ctr. Publ. 809.

Katz, M. and G.A. Ledingham. 1939. Effects of environmental factors on the susceptibility of barley and alfalfa to sulfur dioxide, p. 262-297. In: National Research Council Canada (ed.). Effects of sulfur dioxide on vegetation. Natl. Res. Council Can. Publ. 815.

Loftfield, J.V.G. 1921. The behavior of stomata. Carnegie Inst. Publ. 314.

Mansfield, T.A. 1973. The role of stomata in determining the responses of plants to air pollutants. Commun. Plant Sci. 2:11-20.

Meidner, H. and T.A. Mansfield. 1968. Physiology of stomata. McGraw-Hill, New York.

Mosley, A.R., R.C. Rowe, and T.C. Weidensaul. 1978. Relationship of ozone injury to maturity classification and yield of potatoes. Amer. Potato J. 55:147-153.

Nielson, J.P. 1938. A study of the action of sulfur dioxide on growing plants under various conditions. PhD diss. Stanford Univ., Stanford, Calif.

Olszyk, D.M. and T.W. Tibbitts. 1981. Stomatal response and leaf injury of Pisum sativum L. with $\mathrm{SO}_{2}$ and $\mathrm{O}_{3}$ exposures. II. Influence of moisture stress and time of exposure. Plant Physiol. 67:545-549.

Olszyk, D.M. and D.T. Tingey. 1984. Phytotoxicity of air pollutants. Plant Physiol. 74:999_ 1005 .

Tibbitts, T.W. and J.M. Kobriger. 1983. Mode of action of air pollutants in injuring horticultural plants. HortScience 18:675-680.

Turner, N.C. 1991. Measurement and influence of environmental and plant factors on stomatal conductance in the field. Agr. For. Meteor. 54:137-154.

Ziegler, E., C. Field, and H.A. Mooney. 1981. Stomatal opening at dawn: Possible roles of the blue light response in nature, p. 391-407. In: H. Smith (ed.). Plants and daylight spectrum. Academic Press, New York. 